\title{
O QUE É O NEOJUSNATURALISMO? UM OLHAR PELA ÓPTICA DA ADMINISTRAÇÃO PÚBLICA CONTEMPORÂNEA
}

\author{
WHAT IS NEOJUSNATURALISM? A LOOK FROM THE PERSPECTIVE OF \\ CONTEMPORARY PUBLIC ADMINISTRATION
}

\begin{abstract}
Sandro Lúcio Dezan
Doutorado em Direito pelo Centro Universitário de Brasília - UniCEUB (2016); Doutorado em Ciências Jurídicas Públicas pela Escola de Direito da Universidade do Minho - UMinho, Braga, Portugal (2017); Doutorado em Direitos e Garantias Fundamentais pela Faculdade de Direito de Vitória - FDV (2018), Mestrado em Direitos e Garantias Fundamentais pela Faculdade de Direito de Vitória - FDV (2007); Graduação em Direito pela Universidade Vila Velha - UVV (2000); Professor Titular do Mestrado e do Doutorado no Programa de Pós-graduação Stricto Sensu em Direito e Políticas Públicas (PPGD), do Centro Universitário de Brasília (UniCEUB).
\end{abstract}

\section{Resumo}

O presente texto investiga a interferência do direito natural no direito escrito, declinando a existência de uma normatividade valorativa preconcebida, decorrente do contexto sociocultural, expressando-se como um latente subtexto do direito. Por meio do método hipotéticodedutivo e a partir da premissa da existência e da funcionalidade de um direito contextual, conclui-se que esse fenômeno, para além de sua comum aplicabilidade jurisdicional, estende-se a toda e qualquer função jurídica, a exemplo da função público-administrativa de concreção de direitos. Sob esse vértice, o Estado encontra-se legitimado a lançar mão do emprego de valores axiomáticos, em harmonia com as regras e os princípios jurídicos, para a concreção de direitos, mormente para a realização de direitos fundamentais, permitindo-se falar, assim, em uma face da teoria neojusnaturalista a influenciar a função e os serviços públicos.

Palavras-chave: Concreção de direitos fundamentais. Constitucionalização do direito administrativo. Exercício da função jurídica atípica da Administração Pública. Hermenêutica do direito administrativo. Neojusnaturalismo.

\begin{abstract}
The present text investigates the interference of natural law in written law, declining the existence of a preconceived normative normativity arising from the cultural collective context, expressing itself as a latent subtext of law. By means of the deductive method and from the review of selected bibliography, it is concluded that this phenomenon,
\end{abstract}


besides its common jurisdictional applicability, extends to any and all legal function, such as the public-administrative function of realization of rights. In effect, the State is entitled to use axiomatic values, in harmony with the rules and legal and normative principles, for the realization of rights, especially for the realization of fundamental rights, on one side of the neo-naturalist theory to influence public function and services.

Key-words: An atypical legal function of the public administration. Constitutionalisation of administrative law. Hermeneutics of administrative law. Implementation of fundamental rights. Neojusnaturalism.

\section{CONSIDERAÇÕES INICIAIS}

A percepção de um sistema de direito, no que diz respeito à identificação dos contornos que delimitam a normatividade de um conjunto de estipulações jurídicas gerais e abstratas, dotadas de coerência, coesão e racionalidade, para a regulação das relações interpessoais, passou por diversos estágios nos últimos séculos, na cultura do mundo ocidental. O que é o direito tem sido objeto de inúmeras teorias.

O sentido do direito experimentou noções aprioristicamente fundadas em normas morais e não escritas e, em uma linha de evolução, seguiu-se à sua percepção como normas puramente escritas, ou como normas escritas, mas ampliáveis pela discricionariedade e incursão de princípios jurídicos, e, por fim, ampliáveis por valores axiomáticos.

Nessas balizas, o conceito de direito pervagou para significar ora o conteúdo do direito natural, ora o conteúdo do direito-texto, como o plexo do direito positivo puro, ora ainda o direito positivo mitigado por princípios jurídicos implícitos, e, em um atual e incipiente estágio, o direito positivo axiomatizado. Afere-se, portanto, um direito permeado por valores morais, com o escopo de identificação - o quanto possível - da lei e do direito com a justiça. Permite-se falar em um inicial uso, pela teoria do direito, da combinação de valores e de textos jurídicos, a ensejar o que se caracteriza como uma crise da lei e da legalidade, para um paulatino e adaptado retorno à origem: um retorno à normatividade mitigada do direito natural, o que sugere o nascer de novo do direito natural, a indicar a formação, nomeadamente, da noção de neojusnaturalismo, capitaneada pelo movimento pendular que fez raiar o pós-positivismo de cunho constitucional, o neoconstitucionalismo, e, agora, infere o novo direito natural.

Ao se perceber certas especificidades de mutação da norma jurídica no iter 
percorrido desde o Estado Absolutista ao Estado do Bem Estar Social e, ainda, ao Estado Constitucional de Direito, é irrenunciável constatar que as mudanças de paradigmas (em um sentido fraco da acepção) se operaram em busca de maior segurança jurídica. Assim, a certeza do direito suplantou a justiça desse mesmo direito do Estado.

No entanto, superadas - bem ou malsucedidas - as transmutações paradigmáticas, parece ter o Direito abandonado um de seus fundamentos: a utópica necessidade de segurança. Por outro lado, busca reconhecer limites não mais em um direito escrito, representante do certo e do seguro, para o harmônico convívio social, mas, sim, em um direito justo - o que se afigura não menos utópico que a pretensa segurança.

Havia, destarte, uma tentativa de suprir a ausência de segurança jurídica pela justiça jurídica, em que a primeira era conduzida pelo direito-texto, geral e abstrato, e a segunda, objetivada a partir desse direito positivo, entretanto, atualizável pelas vias da argumentação jurídica, posta a ressaltar os valores normativos, valores axiomáticos - valores estes de cunho moral e juridicamente obrigatórios de serem observados -, que dão fundamento ao direito posto.

Com efeito, o direito positivo não é abolido, para ter mitigada a sua importância final para a concreção das normas do Direito, que é concebido, como um todo normativo, a encampar a lei, como sinônimo de regras e princípios, e os valores juridicizados. Da pretensão de segurança jurídica à pretensão de justiça jurídica, surge a necessidade de afrouxar as amarras da lei, do texto, e, em movimento contrário, arrochar os liames das normas, sem, contudo, fazer tabula rasa das características do direito natural, do direito positivo e do pós-positivismo, para a sustentação da necessidade de retorno à origem da regulação social, ao direito natural. Isto demonstra um movimento pendular do Direito estatal, que, todavia, incorrigivelmente maculado pelas experiências jurídicas da positivação do direito, imprime uma tentativa de fuga dos contornos da lei escrita, para se abeberar no que se permite denominar de jusnaturalismo contemporâneo ou neojusnaturalismo.

Neste contexto, muito mais do que se pode perceber de uma superficial análise, de forma surpreendente, o Direito Administrativo, com a sua reconhecida constitucionalização, e a Administração Pública, submetida para além da lei ao princípio da juridicidade, marcam importantes papeis nessa transposição de paradigmas e, assim, o presente artigo busca demonstrar, conjuntamente com a 
definição dos conceitos e a apresentação das principais características dos institutos ora referidos, o papel da administração Pública no aperfeiçoamento de um neojusnaturalismo administrativo, concretista de direitos.

Para tanto, serão abordados, ao menos indiretamente, os marcos filosóficos e normativos que forçaram a transposição do direito natural para o direito positivo e, não obstante, do direito positivo para o direito pós-positivo e, sem embargo, deste último ao direito natural contemporâneo, pervagando pelo realce do caráter incontornável do direito positivo para as evoluções que se sucederam, a exemplo da teoria de distinção entre princípios e valores de Robert Alexy. Por fim, será investigada, à luz de todo o exposto, o que se pode chamar de fuga da Administração Pública para o direito natural, capitaneada por uma nova hermenêutica constitucional do direito administrativo sob a concepção de uma tentativa de acomodação entre 0 neoconstitucionalismo e o neojusnaturalismo.

\section{OS ESCOPOS DE SEGURANÇA JURÍDICA E DE JUSTIÇA NO DIREITO ADMINISTRATIVO}

Falar em segurança jurídica infere, em uma primeira aproximação, reconhecer a mudança da concepção do direito, como direito natural, para o direito como texto, representativo do direito positivo (VICO, 2005). Do mesmo modo, falar em justiça do direito perfaz compreender a tentativa de superação do positivismo jurídico pelo neoconstitucionalismo, de caráter pós-positivista (ATENCIA, 2005; GARCÍA FIGUEROA, 2006; CARBONELL, 2007).

O direito, em linhas generalíssimas, é um apanhado de normas que reflete o mais profundo e complexo conjunto de costumes de uma sociedade, modalizado para permitir, obrigar ou proibir condutas de interesse do convívio social (GROSSI, 2014, p. 5-9). Como escreve Paulo Grossi, "fisiologicamente, o direito não é (ou nunca apenas é) nem um conjunto de formas que limitam o devir da vida social, nem um conjunto de regras autoritárias para manter o poder constituído" (GROSSI, 2014, p. 5), senão, ao afastar-se da tendência de um mero artifício, é "significado essencialmente ontológico" (GROSSI, 2014, p. 6-7): o direito é o significado da compreensão cultural de ordem ou organização social, aplicado à regulação do convívio coletivo. Deste modo, ele está indissociavelmente ligado às razões lógicas e históricas de um sistema de crenças e de valores (GROSSI, 2014, p. 9). Sob essa óptica, assinala-se que houve e há crenças 
em valores jurídicos, formadoras do que se pode denominar de subtexto do direito, dedicado a moldar e a delimitar, de modo estático e dinâmico (ZAGREBESLKY, 2008, p. 136), os contornos teóricos do direito natural, do direito positivo e do neoconstitucionalismo, com expressão do pós-positivismo, assim como do retorno ao direito natural, como únicos reconhecidos como normativos em seu tempo e, para o Direito Administrativo, como ramo epistemológico, não foi diferente.

O Direito Administrativo possui sua origem como ramo epistemologicamente autônomo nos meados do século XVIII, reportando-se, para a maioria dos estudiosos do tema (WEIL, POUYAUD, 1997, p. 9-22; RIVERO, 2011, p. 25 e ss.; CASETTA, 2011, p. 2-4), ao advento da Revolução Francesa de 1789 e ao movimento constitucionalista. Nessa origem, início do Estado Liberal e marco de ruptura do ancien regime de um modelo de Estado Absolutista, o Estado - e, consequentemente, o modelo de direito - quedou-se adstrito a uma série de dogmas revolucionários (ZANOBINI, 1947, p. 41-45), a exemplo da necessidade de submissão do Estado Nacional à lei escrita, votada e aprovada por um órgão parlamentar, representativo do povo, do coletivo social (MATER, 1949; ENTERRÍA, 1981, p. 9). Nesses vértices, pela óptica da repartição dos Poderes do Estado em razão de suas funções, de criação das leis, de execução dessa ordem normativa criada e de sua aplicação ao caso concreto (FIORAVANTI, 2001, p. 47), fez submeter a Administração Pública, como aparato do Estado-administração, Estado-executivo, ao seu dogma maior: o princípio da legalidade, nomeadamente de caráter estrito, restritivo. Com efeito, o Poder Executivo, assim como os demais Poderes no exercício de função atípica executiva, submetia-se ao princípio da legalidade estrita, vinculante do agir e do omitir-se estatal.

Em que pese a essa origem como marco histórico do surgimento do Direito Administrativo, isto não significou que não existissem normas administrativas, reguladoras das funções afetas ao modelo de Estado representante do ancien régime, que abriram espaço para estudos iniciais dos contornos da disciplina, desenvolvidos por teóricos franceses e alemães, a exemplo de Léon Duguit, Maurice Hauriou e Otto Mayer. Forneceu-se, assim, a base epistemológica do direito administrativo, preparador de terreno fértil ao evoluir doutrinário, para trilhar um iter que perpassa pelo positivismo jurídico e pelo pós-positivismo.

O pós-positivismo, sob os fundamentos do neoconstitucionalismo e sob a óptica pela qual Ihe atribua maior ou menor alcance, busca superar o positivismo jurídico, ou minimizar os seus efeitos inibidores de um verdadeiro estado comprometido com os 
direitos fundamentais, para a tendente transição entre o Estado de Direito Democrático e o Estado Constitucional Democrático. O direito administrativo, como ramo do direito responsável pela normatização de condutas da Administração Pública, conquanto face executiva do Estado para a prestação de serviços públicos, vem sentindo diretamente a tensão provocada pelo início de mudança de paradigmas.

À vista desta breve introdução, as linhas que se ora desenvolvem possuem o objetivo de abordar as causas próximas e as consequências do fenômeno da constitucionalização do direito administrativo, assinalando 0 seu regular desenvolvimento, em consonância com o evoluir das teorias e paradigmas afetos ao direito constitucional. Em seção final, o texto abordará a definição do conceito e os efeitos do que se compreende como juridicidade da Administração Pública, para concluir que o Poder Executivo, em harmonia com as atribuições dos demais Poderes da República, também possui a atribuição de concretização direta de direitos fundamentais.

O Constitucionalismo, como movimento político, ideológico-sociológico e jurídico da segunda metade do século XVIII e de todo o século XIX, forjou os fundamentos, ao menos indiretos (BINENBOJM, 2008, p. 28-29), do direito administrativo, na medida em que se sustentava em uma variante do positivismo científico, deste modo, buscava dotar todos os Estados-Nação de uma Constituição escrita, que trouxesse em seu bojo a forma de organização e de exercício do poder e um rol de direitos fundamentais, notadamente, nesse contexto, ainda os direitos civis e políticos (SARLET, 2007), tidos hoje, como direito de primeira dimensão - esta classificação, conforme ensina Paulo Bonavides (2006, p. 563) - ou geração (BOBBIO, 1970; 2007).

Afere-se, destarte, a íntima relação entre o movimento constitucionalista, o direito constitucional, o direito administrativo e o positivismo jurídico - derivado, porém, do positivismo científico (BOBBIO, 1970; 2007). Como assinalado, Léon Duguit (1889; 1894), Maurice Hauriou (2002; 2012) e Otto Mayer (1948) são autores expoentes cujos estudos contribuíram para a autonomia epistemológica do direito adminsitrativo. Este primeiro momento, gênese do direito administrativo, conforme conhece o mundo ocidental, compreende legado da Modernidade, firmado, assim como o direito constitucional, em uma necessidade de submissão do Estado e dos indivíduos à lei, esta editada pelo povo, diretamente e/ou por meio de representantes eleitos. 
Para além da aspiração político-sociológica da supremacia da comunidade política (FIORAVANTI, 2001, p. 47), o escopo revolucionário foi movido, sob o aspecto jurídico, pelo ideal e de segurança jurídica, pelas vias do direito positivo, do direito escrito, arrimado no dogma da completude do texto de lei, do direito-texto, a afastarse de uma experiência deletéria de exercício do poder com base no direito natural, permeado, a par dos valores morais, pela vontade individual e subjetiva de soberanos, com direito ilimitado para administrar, impassível, assim, de responsabilidade (quod regi placuit lex est; the King can do not wrong, lei roi ne peut mal faire).

Surge, assim, com maior força que os ensaios medievais, o positivismo jurídico em momento simultâneo ao direito constitucional e ao direito administrativo, na gênese do Estado de Direito e Estado Democrático de Direito. O Estado - e aqui, inclui-se também o povo - confiava nessas normas desses dois ramos epistemológicos para o alcance do tão almejado valor "segurança Jurídica" das relações jurídicas intersubjetivas.

Sem embargo dessa inicial necessidade de positivação de leis e de submissão do povo e do Estado a elas - o que se fez necessário no momento histórico -, com o aperfeiçoamento do Estado Liberal, percebeu-se que a lei em si apresenta uma série de problemas que desconstroem o valor segurança jurídica. Viu-se que não seria por meio da lei somente que se atingiria esse escopo, mormente por quer a atividade de hermenêutica jurídica não seguia as mesmas regras abertas da atividade de hermenêutica moral, da filosofia hermenêutica (HEIDEGGER , 1993; STEIN, 2014), da hermenêutica filosófica (GADAMER, 2014) e da hermenêutica argumentativa (STRECK, 2017). Mesmo diante do positivismo jurídico, a lei ainda apresentava vaguezas e obscuridades de sentido e de significado. Tanto que essas características do texto de lei e da ordem jurídica, como um todo, levaram às maiores barbáries experimentadas pela humanidade: as duas grandes guerras do século XX. Provouse, mormente no século XX, que o positivismo jurídico já não mais dava conta de garantir segurança jurídica que pudesse atender às complexas relações sociais e internacionais que se formavam a passos largos.

Com efeito, uma gama de estudiosos passou a sustentar a necessidade de retorno ao passado, de retorno ao direito natural, com a reaproximação entre o Direito (até então concebido, única e exclusivamente, como o texto de lei, o direito-texto) e a moral, em uma nova roupagem do jusnaturalismo, a caracterizar-se como neojusnaturalismo. Que serviria de base para a superação do positivismo jurídico, 
sendo uns dos responsáveis por corrente jusfilosófica hoje bastante estudada: o póspositivismo. Afirmamos, inicialmente, que o direito constitucional e o direito administrativo surgiram de certa decepção com o direito natural e do advento do positivismo jurídico clássico, com o escopo de alcance de uma adequada segurança das relações jurídicas. Sem embargo disso, à vista da superação, ou melhor, de um início ou busca de superação do positivismo jurídico, esses dois ramos do direito (sem embargo de esse fenômeno atingir a todos os outros ramos epistemológicos do direito) sentiram a mudança de paradigma.

O pós-positivismo deu azo a ponto de confundir-se como um novo paradigma, o neoconstitucionalismo, firmado nesse propósito de retorno à origem, com a reaproximação entre o Direito e a moral. No escólio de Luis Roberto Barroso (2005, p. 33-34), três foram os marcos fundantes do neoconstitucionalismo: o marco histórico, o marco jurídico ou normativo e o marco filosófico. O marco histórico é representado pelas grandes guerras do século $\mathrm{XX}$, conforme ressaltado alhures, declinado o insucesso do direito-texto como garantidor de harmônicos convívios, pois ao amparo da lei estrita permitiu o cometimento de barbáries inconfessáveis (ARENDT, 1997). O marco normativo, sob o viés do direito brasileiro, é considerando a partir da Segunda Guerra Mundial, com o advento das Constituições da Alemanha, da Itália, da Espanha, de Portugal e do Brasil. Compreendem diplomas jurídicos formadores de novos Estados-Nação comprometidos com o respeito aos direitos humanos, tendo como princípio jurídico matriz a dignidade da pessoa humana (CANOTILHO , 2002). Some-se a esses textos a Declaração dos Direitos Humanos da ONU, de 1948. Nesse ponto, há de se reparar algo um tanto curioso, qual seja, a fundamentação do pós-positivismo em textos positivados. Isso significa dizer que, por mais que se busque superar o positivismo jurídico, ele é incontornável e ciclicamente agregado à nova concepção de Direito, reafirmando assim o assinalado por Karl Popper (1974) sobre a formação e evolução do conhecimento em espiral.

Por fim, o marco filosófico do pós-positivismo - aqui tratado como sinônimo de neoconstitucionalismo - compreende ideias de que (i) a constituição deveria ser respeitada e encontrar-se acima de toda a ordem jurídica estatal, de modo a conferirIhe supremacia: supremacia da Constituição; (ii) a Constituição deve deter carga de normatividade de seu texto, atribuindo-Ihe força normativa capaz de inferir os modais deônticos típicos das leis infraconstitucionais (HESSE, 1999); e (iii) em razão da natureza das relações humanas intersubjetivas, não se pode pretender - como o 
idealizaram Kelsen (1999) e Hart (2012) - um direito puro, alijado de valorações próprias da essência humana e, por vezes, valorações consequencialistas; um direito não permeado por valores morais é um não direito, desprovido da necessária justiça a qual o Direito deve tributo. Com efeito, o Direito deve ser posto para a concretização da justiça.

Diante desses marcos ou fundamentos surgiu o pós-positivismo a dar azo às bases do neoconstitucionalismo, que elevou a Constituição do Estado a um patamar de norma regente das demais normas e implantou um avançado e complexo sistema de hermenêutico: a hermenêutica constitucional (MÜLLER , 2007, p. 315-317; COELHO, 2012; BARROSO, 2012, p. 55; ATIENZA, 2006; FERNANDEZ-LARGO, 1995; FICHTE, 2012).

A nova hermenêutica jurídica afeta ao direito constitucional não tardou e atingir o direito administrativo, primeiramente na década de 1980 na Europa Ocidental, e após a abertura política de 1988, o Brasil, com o advento da Constituição Federal. Nessa esteia, Ronald Dworkin (2006) assinala que as normas constitucionais são de duas espécies, qualitativamente distintas, os princípios e as regras, em que os princípios possuem a característica de mandamentos de otimização, devendo ser concretizados o máximo permitido pelo direito, ao passo que as regras se caracterizam por serem mandamentos de concreção, submetendo-se ao escopo do tudo ou nada, compreendendo a validade ou a invalidade. A partir dessa formulação teórica de Dworkin, Robert Alexy concebeu a sua regra da ponderação, sustentada com a idealizada fórmula do peso, com incursão na teoria do Ótimo de Pareto, para propiciar a resolução de casos complexos, a partir de ponderações de princípios constitucionais colidentes à luz do caso concreto (ALEXY, 2008).

Esses são dois exemplos de mudança de paradigma apresentado pela hermenêutica constitucional, a partir do advento do neoconstitucionalismo. Muitos ostros exemplos podem ser obtidos, mas a nós, nos interessa apenas ilustrar tal transição que, primeiramente surgiu no direito constitucional e à vista de suas normas carregada de valores e que, paulatinamente, vêm se estendendo para erigir o direito constitucional, cada vez mais, ao centro do sistema epistemológico e, sem embargo, ao centro do sistema da hermenêutica do Direito, no qual se insere o direito administrativo, a ponto de se falar até mesmo em fuga do direito administrativo para $o$ direito constitucional, concepção com a qual não concordamos, pois preferimos entender o fenômeno como uma Constitucionalização do Direito Administrativo, como 
efeito ordinário e esperado de um Estado Constitucional e Democrático de Direito, a se avolumar nas duas últimas décadas do século XX e nestas duas primeiras décadas do século XXI.

Em apertada síntese da definição do conceito de Constitucionalização do Direito Administrativo pode-se considerar, pela óptica política, a redução de ingerências do legislador ordinário no processo de execução da lei pelo Poder Executivo e pela Administração Pública, vinculando-se os entes e órgãos públicos, primeiramente, ao Poder Constituinte, Originário e Derivado, para a concreção dos fins público-administrativos. Pela óptica jurídica, a constitucionalização do direito administrativo força a retirada da lei como intermediária entre a Constituição e a execução dos fins da Administração Pública.

\section{OS RESQUÍCIOS INCONTORNÁVEIS DO POSITIVISMO JURÍDICO EM UM ESTADO CONSTITUCIONAL E DEMOCRÁTICO DE DIREITO}

Por mais que se busque aproximar o direito da ética e da moral, com o escopo de justiça decorrente dessa relação, para a aplicação ao caso concreto em um juízo de justificação (GÜNTHER, 2004), o positivismo jurídico há de ser firmado como o ponto de partida dessa simbiose, em um movimento espiral de compreensão e reação (POPPER, 1974), que se forma entre o direito-texto e os valores que the servem de fundamento para a concreção da norma jurídica.

O neoconstitucionalismo não logrou e, sem embargo - ao menos em linhas teóricas -, não pretende suplantar o juspositivismo como marco inicial de sua aferição de concretude das normas jurídicas ${ }^{1}$. Não se há de pensar que o fenômeno da constitucionalização do direito, à vista da nomeada característica de refutação do valor da lei frente ao valor maior da Constituição, faz tábula rasa da função prescritiva da lei. O neoconstitucionalismo, por mais que se amolde aos cânones do pós-positivismo, não ignora o direito-texto como seu ponto de partida de uma normatividade latente, tanto que se apega ao conceito de Constituição escrita e à premissa de sua força normativa, para deferir maior relevância ao seu texto (o texto constitucional: aparente e subaparente) e ao seu conteúdo axiomático, frente ao texto do direito escrito infraconstitucional. Essa é a real característica do pós-positivismo de matriz

\footnotetext{
1 Defendendo a não superação do positivismo jurídico pelo neoconstitucionalismo, cf. Lopes Filho e Lobo, (2019, p. 348-361).
} 
neoconstitucionalista, a de transferir para a Constituição escrita o centro do direito posto, formando o conceito de Estado Constitucional de Direito (BARROSO, 2002; 2004). E aqui reside a distinção entre neoconstitucionalismo e neojusnaturalismo senão vejamos.

Sob a óptica do neoconstitucionalismo as normas jurídicas são das espécies princípios e regras (DWORKIN, 2001, p. 41 e ss.; e 2010, p. 23 e ss., 73 e ss.), em que os princípios compreendem mandamentos de otimização ao passo que as regras comportam mandamentos de concreção. Os primeiros, dotados de alta carga valorativa, comportam estratos de ponderação e distinguem-se, assim, qualitativamente da segunda espécie, as regras, que, desprovidas de fundamentos valorativos, impõem a aplicação sob um modelo de tudo-ou-nada, submetendo-se ao all-or-nothing-fashion (ALEXY, 2008, p. 85-179). O neoconstitucionalismo considera a força normativa dos princípios jurídicos, como espécies de normas jurídicas, para, indiretamente, propiciar a aplicação de valores, que ingressam no direito por essa via: o princípio jurídico perfaz o papel de porta de entrada dos valores para o mundo jurídico. Com efeito, como assinalado, a aplicação de valores no âmbito jurídiconormativo se opera de modo indireto, por interposição de princípios jurídicos, positivados, mormente, na Constituição, como texto normativo ápice do ordenamento. Por sua vez o neojusnaturalismo desconsidera essa divisão bipartida da norma jurídica em princípios e regras e inclui os valores nesse meio, para formar um tertium genius, também de caráter vinculante, qual seja, o valor juridicizado. Este já é concebido no campo da normatividade do direito em sua gênese, operando diretamente e em conjunto com as outras duas espécies de norma.

As consequências disso são tremendas: o valor, aferível como deôntico em um contexto sociocultural passa a ter o condão de obrigar alguém a fazer ou deixar de fazer alguma coisa. À vista disso, o valor jurídico, como espécie de norma jurídica, passa a compor a forma vinculante de um sistema de normas que, na essência, faz um retorno, ou uma fuga, para o direito natural, porém mitigado pelo ponto de partida, o direito-texto (a lei escrita, geral e abstrata). O Estado Constitucional de Direito aceita o neoconstitucionalismo e, do mesmo modo, o neojusnaturalismo. Não é ele incompatível com um ou com outro e isto representa uma faceta do neopositivosmo (ATENCIA, 2005; GARCÍA FIGUEROA, 2006; CARBONELL, 2007). Entretanto, a evolução do conceito de direito pede esse retorno à origem, qual seja, a revalidação do emprego do direito natural, em sua face dos elementos de ética e de moral, com 
maior veemência, ao direito-texto, quer seja ele constitucional ou infraconstitucional, com o escopo de realização, ao máximo possível, da justiça do direito, ou seja, da justiça pelas mãos do direito, para além do direito positivo.

Sob esses vértices que realçam um imbricado enlace entre o positivismo jurídico e o neoconstitucionalismo, há de se notar que caminham juntos o direito positivo e o direito natural, a declinar a incontornabilidade do positivismo jurídico, mesmo ao se falar em neoconstitucionalismo, forma de pós-positivismo jurídico.

Por isso que não se defende em emprego do direito natural pura e simplesmente, mas sim em um novo modelo de Direito, formado pelo direito positivo aperfeiçoado pela hermenêutica jurídica, a expor os valores fundamentais do direito como contexto social ético-moral e, assim, a ressaltar o subtexto do direito - o fundamento para além de uma razão suficiente -, o que se afere como o direito como contexto: o direito contexto.

\section{PRINCÍPIOS JURÍDICOS E VALORES NA TEORIA DE ROBERT ALEXY: UM PONTO DE TRANSIÇÃO ENTRE O POSITIVISMO JURÍDICO E O NEOJUSNATURALISMO}

Com o amadurecimento do positivismo jurídico e o corolário advento do póspositivismo (que, sob a sua concepção mais comum, nada mais é que um aperfeiçoamento positivista), os princípios jurídicos, conforme ensina Ronald Dworkin (2012), passaram a ser reconhecidos como espécie do gênero norma jurídica, ao lado das regras, apresentando-se ao intérprete e aplicador do direito como mandamentos de otimização, ao passo que as regras firmaram-se como mandamentos de concreção (DWORKIN, 2010). Sob esse novel vértice de cunho nomeadamente neoconstitucional, delineou-se a percepção de direito, a partir do reconhecimento da força normativa da constituição, como o contexto de normas de duas espécies: os princípios, compreendendo as prescrições escritas, expressas ou implícitas, na ordem normativa (no direito-texto), compostas de certa carga valorativa ou de um valor fundante - os princípios são, destarte, normas valorativas (que trazem um valor latente) e, diante dessa característica, admitem uma métrica, uma gradação de aplicação, para a sua realização à luz do caso concreto, facultando-se the exarar efeitos em intensidade diversa, a depender de sua prevalência material, concreta para o caso. As regras, por seu turno, são identificadas com a descrição textual fechada do 
normado, de modo a não permitir valorações e decorrentes gradações de efeito, pelo intérprete e aplicador (ALEXY, 1993, p. 138-139).

No escólio de Robert Alexy, há uma distinção não quantitativa, mas sim qualitativa entre princípios e regras. Na constatação de incidência da primeira espécie, em caso de conflito de normatividade, há de se aferir, ao amparo do caso concreto, o princípio prevalente a servir ao exegeta para a obtenção da norma concreta, sem, contudo, exarar um efeito jurídico de invalidade sobre os demais princípios colidentes e não prevalentes. Com efeito, principios prevalentes e não prevalentes incidentes sobre um mesmo caso não se anulam, mas os prevalentes exercem efeito de normatividade excludente da normatividade dos princípios não prevalentes. Essa questão é resolvida por Alexy com o emprego da fórmula do peso, em que essa ratio é expressa em forma de fundamentação que propicia a identificação do princípio prevalente que normatizará o caso concreto examinado.

Apesar de assegurar que princípios são formados por valores, com estes não se confundem, pois os valores não pertenceriam ao mundo deôntico, mas ao mundo axiológico. Com efeito, princípios materializam valores no campo deôntico do direito, sem perder a sua capacidade de valoração ou de graduação pelo aplicador do direito, diante de um caso concreto, característica não atribuível aos valores, cuja eventual gradação quedaria ao campo do subjetivismo e, assim sem normatividade deôntica. Por essa via, em que pese à possibilidade de colisão e de ponderação entre valores (ALEXY, 1993, p. 138-139) - a exemplo do que ocorre com os princípios: colisão e cumprimento gradual -, um e outro pertencem a campos distintos: os princípios, afeto ao campo deôntico, ao mundo do dever-ser; os valores, ao campo axiológico, extrajurídico, subscrito ao conceito do poder-ser (qualificação do que é) bom. Encerram os princípios o conceito deontológico e os valores o conceito axiológico. Os princípios são mandamentos, mandamentos de otimização, e os valores são juízos sobre algo (ALEXY, 1993, p. 141).

Sem embargo, os valores podem ser definidos como visto, como juízos sobre algo (ALEXY, 1993, p. 143). Alexy explica que o enunciado sobre o valor de algo, seguindo uma regra de valoração ou um critério de valoração, é um juízo de valor, uma valoração, que compreende uma classificação, ou uma comparação ou, ainda, uma medição. Com efeito, há juízos de valor de natureza classificatória, comparativa e métrica, incidentes em objetos, ações, características, etc (ALEXY, 1993, p. 142).

Os juízos classificatórios de valor dizem respeito à distinção entre os valores, 
por exemplo, relativos ao bem e mal, ao belo e feio, ao justo e injusto, ao seguro e inseguro, ao melhor e pior, ao econômico e não econômico, etc; incluindo, ainda, a modalidade neutra (ALEXY, 1993, p. 142), e.g, seguro, inseguro e neutro, justo, injusto e neutro, etc. Os juízos comparativos de valor referem-se a dois valores comparados entre si, indicando que algo é melhor, pior ou igual a outro, como no exemplo de se afirmar que a Constituição do Brasil de 1988 é melhor que a Constituição do Brasil de 1946, ou pior ou igual. Os juízos métricos de valor correspondem à eleição de uma gradação que permite transpassar de uma característica para outra oposta (justo para injusto; seguro para inseguro, melhor para pior e vice versa). Isso se daria, por exemplo, ao se afirmar que os veículos automotores que ultrapassam a velocidade de $120 \mathrm{~km} / \mathrm{h}$ são rápidos e os que não atingem essa marca são lentos. Note-se que há uma gradação que varia do valor lento para o valor rápido a depender de um indicador, de uma marca.

Esclarece Alexy que esses juízos classificatórios de valor, pertencentes ao campo axiológico, não são transponíveis a posteriori - por via de um juízo de fundamentação - para o campo jurídico-deôntico. Essa também é a leitura de Klaus Günther (2004). Com efeito, apesar de os valores comportarem-se como normas inclusive com um caráter bipartido formado por regras de valoração (regras) e critérios de valoração (princípios) (ALEXY, 1993, p. 144) -, não são dever-ser, não são normas deônticas. Assim, Alexy ilustra a relação entre normas deônticas e valores com o seguinte esquema:

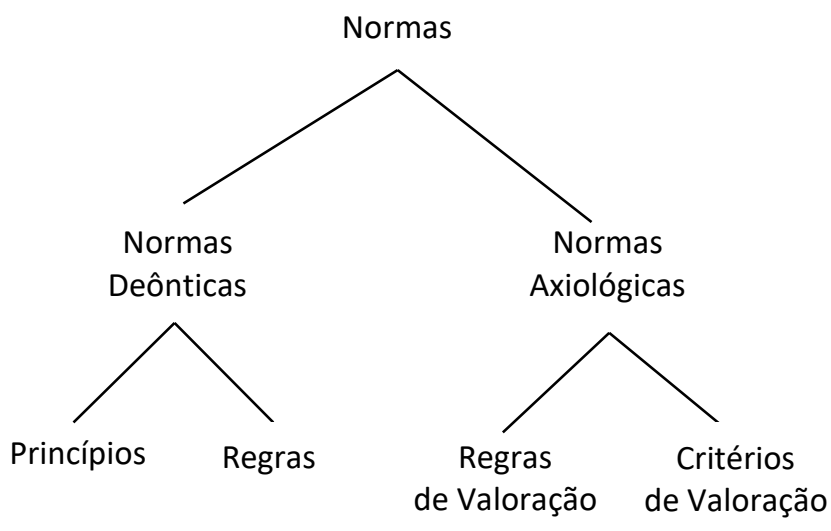

À vista da teoria de Robert Alexy, sobre a distinção entre princípios e valores, a diferenciação reduz-se à constatação de que princípios são deontológicos e valores são axiológicos (ALEXY, 1993, p. 147).

Com efeito, definitivamente, para Alexy, os valores, apesar de influenciarem a 
ponderação de princípios jurídicos, não são jurídicos.

Em que pese às constatações de Alexy e a par das aproximações e distinções apontadas entre princípios jurídicos e valores, a nosso sentir há, ainda, uma peculiar relação entre eles, em que se concebe a função fundamental dos valores ao aporte dos princípios, representada pelo seguinte diagrama:

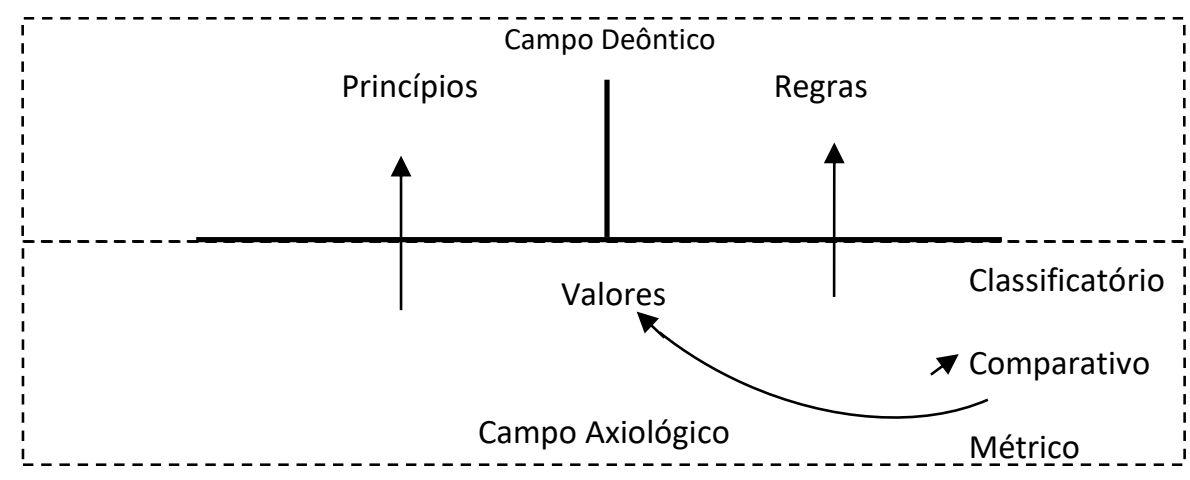

De acordo com o quadro, os valores funcionam no campo pré-deôntico, axiológico, como fundamento dos princípios e das regras jurídicas, prestando-se a figurar como origem remota das normas jurídicas - estas afetas ao campo deôntico, pós-axiológico. Sem embargo, como veremos no item seguinte, os valores, para além de funcionarem como antefundamento dos princípios jurídicos, podem ser deônticos, o que classificamos como valores axiomáticos.

\section{NEOJUSNATURALISMO: O DIREITO CONTEXTO APLICADO PELA ADMINISTRAÇÃO PÚBLICA}

Diante do exposto no item 3 , em que pese à possibilidade e o dever de concretização de direitos abstratos positivados - afetos à jurisdição, pelo Poder Judiciário, e à juridicidade, pela Administração Pública -, não somente à realização de direitos fundamentais queda adstrita esta atribuição. $O$ exame de valores axiomáticos (ou jurídico-axiomáticos) e, assim, deônticos por uma óptica fenomenológica, leva a algo mais: propicia encarar o Direito à luz dos fatos e não os fatos à luz do Direito. Busca-se com isso dizer que o mundo do dever-ser deve respeitar, por óbvio, as limitações impostas pelo mundo do ser: o deôntico subjaz ao ôntico (SCHELER, 1933, p. 112-114)2.

\footnotetext{
2 Essa inversão deve ser obstada. Findlay (1969, p. 15-16), em passagem filosófica que muito se aplica ao que se ora comenta, escreve que "la antinomia, en otras palabras, es un fenómeno que lo invade
} 
Valores são padrões normativos vinculativos mais diretamente relacionados aos fatos em si e devem, com efeito, ser observados pelo intérprete e aplicador do Direito. Não se defende aqui qualquer espécie de valores objetivos a-históricos, universais e existentes no mundo independentemente do humano. Neste ponto específico, concorda-se com a crítica formulada por João Maurício Adeodato, ao reportar um suposto equívoco de Max Scheler e Nicolai Hartmann em passagens de suas teorias dos valores, que veemente defendem uma "doutrina axiológica objetivista, segundo a qual os chamados valores não são criação humana, mas existem no universo independentemente de serem ou não realizados, compreendidos ou sequer percebidos por quem quer que seja" (ADEODATO, 2013, p. 42). Particularmente, posicionamo-nos intermediariamente, não de forma dogmática, como o faz Adeodato, e, por outro lado, também não de modo axiológico objetivista universal, mas sim de modo a considerar o valor juridicizado por um cariz temporalizado, ora mais, ora menos perene, pela fusão de horizontes em Gadamer (2014), para um locus de historicidade, a declinar objetividade enquanto ôntico e ontologicamente verdadeiros e válidos, para determinado contexto sociocultural. Esses padrões juridicamente materializáveis e passíveis de exame valorativo pelo intérprete-aplicador do Direito, por meio da hermenêutica argumentativa, inserem-se no contexto da decisão administrativa independentemente de positivação expressa e direta do Direito em suas concepções textuais prescritivas infraconstitucionais. Isso se desvela devido à acolhida de normatividade latente (a ser revelada pelo intérprete) e funcional (posta à concreção da justiça a que se propõe o direito positivo), contida na própria Constituição, nas subcamadas ou entrelinhas fundantes do Direito como texto normativo, e, sem embargo, irradiada para todo o sistema de normas jurídicas.

Tais subcamadas fundantes do direito posto, uma vez operacionalizadas por meio de procedimentos adequados, ou seja, externamente por meio de um devido processo legal, e, internamente, por meio do exercício de uma racionalização compreensiva ôntico-ontológica, conjuntivos e propensos à apreensão de valores, compatíveis e complacentes com uma procedimentalização geral de métodos de juridicização, para as valorações jurídicas que, ao amparo do caso concreto, devem ser convertidas em linguagem (simultaneamente em um círculo hermenêutico e em

todo en el mundo experimentado e interpretado, y viene a ser más y más aguda cuanto mayor es nuestro intento de poner los fenómenos claramente en un foco, de verlos a una luz incambiable, plenamente reveladora". 
um círculo argumentativo) e, assim, também devem subsidiar de modo direto, como mais um instrumento jurígeno, o agir jurídico, jurisdicional, do Poder Judiciário, e, de todo modo, do Estado-administração. Insiste-se aqui em afirmar que à Administração estatal, no exercício de sua função atípica de caráter jurídico, também constitucionalmente se the atribui - a exemplo do Poder Judiciário, todavia com outros instrumentos distintos da jurisdição - a função de efetivação integral do Direito, quer seja ele o apreendido do próprio direito-texto (do texto constitucional e/ou das leis e dos regulamentos), quer em complemento ao direito-texto, em uma apreensão do direito contexto. Eis aqui uma face de expressão do neojusnaturalismo pela óptica da Administração Pública. Pretende-se a inserção de conteúdo objetivo, ou seja, de objeto material, ou de substância, ao procedimento estatal. Empenha-se, assim, na materialização e na substancialização dos instrumentos postos à disposição do Estado para a realização de seu escopo atípico de aplicação do Direito ao caso concreto.

$O$ que se quer afirmar como procedimentos adequados compreende a aceitação da tese de que o fenômeno, em um plano ontológico, em forma de um projeto do Dasein (HEIDEGGER, 1993), "se dá fundado em sua originária abertura em que ele se encontra junto aos entes em geral" (CUNHA, 2014, p. 202) e, com efeito, "na própria estrutura da transcendência ele será fundado e fundamentado" (CUNHA, 2014, p. 202) e, nessas balizas, o homem compreende, interpreta e fundamenta de forma simultânea e pré-linguística, e, num plano ôntico-linguístico, "a apreciação dessas estruturas ontológicas no plano do Direito é não somente possível, mas determinante" (CUNHA, 2014, p. 202), o que se denomina de coimplicação dos planos ôntico e ontológico (CUNHA, 2014, p. 202). Nesse contexto, as razões argumentativas se movimentam para a compreensão flexível conformadora do circulo hermenêutico, de Gadamer (2014) que se aperfeiçoa com a hermenêutica argumentativa e o sentido a priori da linguagem que sempre restará fundado e fundamentado, em outro contexto: o círculo argumentativo.

Com esse propósito de busca de profunda eficácia normativo-social, com a efetividade do normatizado pela concreção integral do Direito vigente ao amparo do sistema de normas e do contexto do Direito, por via, também, de valores axiomáticos, desenvolve-se - ou ao menos se intenta trazer ao debate - uma teoria dedicada (i) a ampliar, ao tempo em que por via reflexa a enclausura, a atribuição discricionária do Estado-administração, e, ainda, por outras palavras, (ii) a submeter a sui generis 
requisitos de efetividade e de eficácia a margem de movimentação argumentativa (o que muitos entendem como discricionariedade administrativa) imanente da hermenêutica decisional administrativa, para a concretização de direitos, não só fundamentais, como, também, gerais regulatórios do coletivo social e, até mesmo, contralegais, contrários a direitos fundamentais formais, não substanciais.

Sem embargo da atuação decisional jurisdicional, firma-se nessas balizas o reconhecimento dos contornos de um maior compromisso do setor público executivo, mormente das instituições responsáveis pela concreção da lei em suas instâncias decisionais - órgãos e autoridades administrativas responsáveis pela edição de decisões administrativas -, não, como atualmente se vê, com a eficiência tardia das condutas de cumprimentos legais, mas sim com a efetividade de posicionamentos capazes de concretizar, de forma fática e acabada, v.g., as políticas públicas ancoradas, necessariamente, em caros temas de direitos constitucionais fundamentais. Deixa-se o plano da eficácia jurídica (BARROSO, 2002; e 2004) isolada - e, também, da tradicional eficiência (BARROSO, 2002; e 2004) -, para adentrar ao plano da eficácia social ou da efetividade (BARROSO, 2002; e 2004) de direitos fundamentais ainda, na práxis, meramente enunciados.

A efetividade de direitos e dos direitos fundamentais por obra ativa do Estadojurídico-administração e como um plus à eficiência estatal pressupõe procedimentos substancializados, permeáveis por valores a serem juridicizados. Busca-se reconhece, com efeito, uma própria deontologia dos valores e, assim, uma espécie de norma jurídica deôntico-axiomática. A matéria e a forma jurídicas são igualmente importantes nesse labor. Não há de reparar uma dicotomia entre substancialismo e procedimentalismo, mas sim uma conciliação, uma unicidade de conteúdo e função a dar azo, por deferência de status de igual importância desses elementos extrínsecos e intrínsecos, à aferição e ao alcance de uma justiça, apesar de axial, temporal, universalmente possível e concretizável pelo Estado.

Para a factibilidade lógica do que se ora propõe, apresentam-se com peculiar relevo os princípios jurídicos, explícitos e implícitos, diretos e indiretos, (i) base do sistema normativo, e, por inovação, os valores políticos e jurídicos em sentido estrito, (ii) pré-jurídicos vertidos em base do sistema normativo, todos juridicizados e fundantes do direito positivo como texto legal (valores axiomáticos, formadores do direito normativo, ou do direito-contexto), na medida em que são os limites das molduras de normatividade lançados à aplicação pelas autoridades encarregadas das 
regras de decisão, para a obtenção dos provimentos executivos. Esses atos administrativos em muitos casos são dotados de caracteres também normativos concretos, não gerais e não abstratos, e, assim, definitivos, malgrado não se tratarem de órgãos jurisdicionais; sim executivos, a proferirem as decisões estatais.

Com a utilização de princípios e de valores juridicizados por meio da adequada razão jurídica à luz da fenomenologia do direito, para a fundamentação de atos de decisão jurídica, dentre os quais se inserem os atos administrativos decisionais, possibilitar-se-á uma maior densificação do plexo de normatividade do resultado final do atuar do Estado-jurisdicional e do Estatal-executivo, que, neste último caso, denomino de juridicidade administrativa. Perceba que se inserirá um novo conceito operacional: a juridicidade administrativa.

Além de propor, com base na fenomenologia, uma dogmática jurídiconormativa extra direito-texto, empenho-me, em um primeiro momento, em desenvolver (i) uma abordagem estabelecida em diretrizes que, prima facie, reconhece o deverpoder de exegese ou de ação interpretativa autônoma da Administração Pública proativa (ação de compreensão / interpretação / fundamentação conjuntiva do Direito) (CUNHA, 2014, p. 155 e ss.; e 2015, p. 139 e ss.), desarraigado das amarras da cega submissão ao suposto texto da lei (sempre geral e abstrato para a Administração Pública, mesmo quando em vias de concretização da lei por via decisional, para a execução de seus comandos normativos), na medida em que se submete, a exemplo do Poder Judiciário em sua atividade jurisdicional, à norma haurida do texto interpretado.

Em um segundo momento, possível identificar, por corolário do primeiro empenho, (ii) a ampliação da autonomia da atividade hermenêutica administrativa publicística que, entretanto (por reflexo paradoxal de uma busca por eficiência e efetividade decorrentes do adequado exercício de suas funções executivas, ao se valer de "ingredientes" incomuns, porém de elevado pragmatismo e plasticidade amoldados concretamente ao contexto de atividades que exigem rápida resposta do Estado), leva ao ato administrativo ótimo ou à melhor decisão, à decisão "historicamente" correta (em um contexto temporal, histórico-sócio-cultural), para a eficiente gestão da coisa pública.

De plano, mister esclarecer que por partir do pressuposto de a razão juridicizada, a razão jurídica histórica sob um cariz fenomenológico, moldar os efeitos normativos socialmente adequados para o caso concreto, o que insere a investigação 
sob color nas perspectivas heideggeriana e gadameriana, integro-me, também, todavia de modo bem reflexo e tangencial, à tese dworkiniana (DWORKIN, 2005) da possibilidade de consecução da única resposta jurídica correta contextualizada, exarada com essa pretensão sob um contexto temporal e sociocultural específico, finito e determinado, existencialista e legado pela fusão de horizontes, para regular eventual relação jurídica intersubjetiva, submetida ao exame jurídico de determinada ordem normativa. Sem embargo do exposto, desenvolve-se, como "pano de fundo" e dentro dos limites teóricos abarcados por uns e outros, uma possível conciliação teórica entre os autores referidos. A tese ora esposada, de tudo, propicia a constatação de essa melhor decisão, baseada no ato jurídico, jurisdicional ou administrativo ótimo, ser plenamente aplicável a toda e qualquer decisão, inclusive às decisões administrativas, figurando - ciente de que um tanto pretensiosa para o direito brasileiro - como uma teoria geral das decisões da Administração Pública.

A partir da visão do agir administrativo como fenômeno de estudo projetado para adiante do conhecimento científico natural e, sob essa óptica, nos moldes da fenomenologia para além da ideia fundamental da constituição, construção, desconstrução e reconstrução do objeto de investigação na consciência, cindidos, todavia, o sujeito e o objeto (HUSSERL, 2007), para firmar que a compreensão, a interpretação (GADAMER, 2014) e a fundamentação (CUNHA, 2014) se dão em um mesmo momento, os métodos e as técnicas de pesquisa sustentaram-se em um pensar abstrato da essência finalística, teleológica, do procedimento e do ato de decisão das autoridades judiciárias e administrativas à luz da revisão bibliográfica de textos doutrinários e da legislação.

Como resultado, constatar-se-á, inclusive por meio de enunciação lógico-formal meramente ilustrativa de corroboração do discurso argumentativo, que o ordenamento jurídico (sem se descurar das prescrições do texto constitucional, dos enunciados de direitos fundamentais, e da legislação ordinária), independentemente de qualquer necessidade mais eloquente de materialização direta da prescrição normativa em questão, mas considerando os valores, conceitos axiais e axiológicos, oferecidos pelo próprio sistema de normas a partir da Constituição como seu texto mais elevado (concepção axiomática jurídico-normativa, ou denôntico-axiomática do Direito), propicia ao Estado - e agora já se fala diretamente na decisão público-administrativa -, no exercício de sua atividade executiva de concretização de políticas públicas constitucionais gerais - e aqui se inserem as de direitos fundamentais -, uma atuação 
vinculada e pautada na proatividade concretista responsável (não há que se falar em qualquer decisionismo jurídico, pois a própria visada fenomenológica impede essa projeção desarrazoada do Direito), garantidora de tomadas de decisão e de gestão de risco com a eficiência e a celeridade que os assuntos executivos passaram a requerer nas últimas décadas, frente aos avanços científicos e à crescente crise da Modernidade.

À vista do exposto, uma advertência se faz necessária: a de que não se defende aqui, por ora, a necessidade de implantação de vias estatais de contenciosos administrativos jurisdicionais a exemplo de algumas instituições jurídicas de países europeus (o que também, por outro lado, não se faz óbice; entretanto este não é o objetivo da presente investigação), mas a imprescindibilidade da realização de procedimentos decisionais, judiciais e - no caso específico que ora me detenho à pesquisa - administrativos, orientados pelos pressupostos de adstrição às subcamadas fundantes do direito posto. Com isso, sem receito de excesso na tarefa hermenêutica e argumentativa do Direito, imperioso ainda se faz afirmar que a correta identificação dos valores jurídicos, adequados aos mais variados temas submetidos ao labor da Administração Pública, leva à apurada concretização de direitos e de políticas públicas de direitos e de direitos fundamentais, sem a necessidade do aguardo de eventual confecção de norma legal que venha a verbalmente (ou de forma escrita, literal) atender ao caso concreto, o que, por vezes, despreza a urgência necessária requerida pelo fluente e complexo convívio coletivo. $O$ valor axiomático percebido como deôntico (reconhecimento do dever-ser de essência do ser), ao amparo de uma projeção fenomenológica já supre essa pseudolacuna normativa.

Por exemplo - e o que aqui se afigura como uma temática de forte juridicidade administrativa - respeita a uma suposta normatividade jurídica do que se concebe como precaução ambiental, na medida em que, independentemente de positivação direta, possível se faz o vislumbre de seus contornos jurídicos por meio da hermenêutica público-administrativa, à vista de uma macronormatividade facilitada pela juridicidade administrativa. Este instituto, que alguns o alocam na categoria dos princípios jurídicos, torna possível um olhar fenomenológico de abertura à fundamentalidade ôntica da estrutura do que de essência há de jurídico-normativo ao amparo do caso concreto. Nesse caso, o proposto instrumentaliza - não como método em seu sentido estrito de caminho científico único, a ser seguido para a demonstração da verdade, mas como novo vértice de possibilidades - o Estado-administração ao 
eficiente e eficaz exercício de sua função atípica julgadora de Estado, concernentes às responsabilidades por decisões jurídicas, em casos determinados por lei.

Esse fenômeno a requerer a instrumentalização por meio da hermenêutica jurídica para a concreção adequada e célere de direitos pode-se dar com outros temas, v. g., a constatação de inconstitucionalidade de leis; a necessidade de juridicidade contra legem, malgrado determinada lei contrariada ser plenamente constitucional; e a constatação de interpretação constitucional e ou legal ilegítima, inválida ou infundada efetivada por órgãos externos à Administração e tendentes a vincular o aparato estatal, a exemplo do discurso pseudodoutrinário que busca limitar o exercício de juízo de valor das autoridades de polícia judiciária, no curso da investigação criminal, quanto ao alcance fundamental jurídico do ato de indiciamento do investigado e do relatório final conclusivo da investigação criminal. Assim, verificase que não se trata de uma questão jurídica pontual, mas sim de um problema de caráter prático, que abarca uma infinidade de áreas sensíveis submetidas ao deverpoder decisional da Administração Pública e que merece uma melhor atenção da academia.

Cite-se ainda, nos mesmos parâmetros do direito ambiental e dos exemplos já agora referidos, a aplicação da juridicidade à concretização de políticas públicas na área da saúde, em que se permite identificar o direito de acesso à saúde e o dever de tutela administrativa desse direito a dar margem de movimentação aos fundamentos da decisão do próprio Estado-administração, para que, v. g., custeie a compra de medicamentos, o remanejamento de recursos de dotações orçamentárias distintas e sem previsão legal para atendimento de solicitação concreta de pacientes do Sistema Único de Saúde - SUS, ou, de outro modo, determine a internação de pacientes em leitos de hospitais públicos - ou em estabelecimentos de saúde privados, mediante indenização estatal -, sem a existência de vagas ou contra as normatizações contrafáticas. Anote-se ainda como expressão de tutela do direito à saúde, a decisão administrativa de não observância da ordem de atendimento (fila), em seus próprios leitos de hospitais públicos, em razão da gravidade (necessidade e urgência real) dos pacientes. Tais casos são face do fenômeno normativo da juridicidade contra legem, cujo emprego impõe-se à Administração Pública, para a efetiva salvaguarda do direito em questão: direito fundamental de segunda dimensão.

Em uma análise mais detida, em essência, esses são exemplos de possíveis casos não de sustentação de atuação contra legem com vista à consideração desses 
fatores reais, mas sim de defesa da atuação administrativa preater legem e, sem embargo, secundum legem, na medida em que não se opõem aos preceitos das leis em questão, mas, tão somente, harmonizam-nos aos próprios casos concretos pertinentes, em que a juridicidade administrativa afigura-se como meio adequado à concretização do direito posto, a completar a ponte da racionalização jurídica, por meio de um verdadeiro elo entre o real e o formal.

Assim, por exemplo, nos dois últimos casos referidos, quais sejam a constatação de improdutividade das terras rurais e o reconhecimento de miserabilidade do indivíduo perante a Autarquia Previdenciária, apresenta-se a juridicidade administrativa como técnica instrumental à aplicação fenomenológica do Direito. Para a constatação de improdutividade das terras rurais, a considerar os fatos adjacentes aos formalizados, a juridicidade emprega-se como instrumento de desvelamento da real situação das propriedades. No que tange à averiguação da condição de miserabilidade do indivíduo perante o INSS, a juridicidade opera para atribuir efeitos jurídicos a todos os critérios fáticos capazes de condicionar a concessão do benefício previdenciário, na medida em que tende a harmonizar os preceitos e critérios trazidos no texto à sua real finalidade social e sistêmicoconstitucional.

Por outro giro, a juridicidade contra legem se afigura na medida em que a Administração Pública se depara com eventual constatação de inconstitucionalidade de lei interpretada e o agente administrativo, apesar de seu dever de adstrição à lei (princípio da legalidade estrita atinente à Administração Pública), recusa o seu "fiel" cumprimento, com base em ofensa dessa lei à Constituição. Aqui, revela-se outra óptica da validade de exercício da juridicidade contra legem. Dentro de dois preceitos antagônicos, prima-se por amenizar o princípio da legalidade, por meio do princípio da juridicidade, e, destarte, não observar uma determinada lei específica, sob o viés de um determinado o caso concreto, com vistas a garantir a higidez do texto constitucional (princípio da unidade e coerência do texto constitucional, em contraposição ao princípio da legalidade administrativa). Preserva-se, com efeito, a noção de sistema jurídico, a sua unidade e a sua estrutura hierárquica, com base na norma hipotética fundamental e na Constituição como ápice do sistema de direito positivo, em detrimento de uma determinada norma que, in concreto, demonstrou-se em desarmonia com os fundamentos da ordem normativa.

A par do exposto, duas espécies de juridicidade contra legem se ora figuram 
no entorno da questão: (i) aquela exercida sem a constatação de inconstitucionalidade da lei não aplicada (que aqui já se referiu como juridicidade secundum legem (ou praeter legem, não importa), e que se permite classificar, mais apropriadamente, como "juridicidade ad normam iuris", ou seja, segundo a finalidade da lei); e (ii) aquela exercida com a constatação de inconstitucionalidade da lei não aplicada - juridicidade contra legem em sentido estrito. Disso se constata uma tentativa de frustração do natural aos moldes do legal idealizado, ou mesmo, aos moldes do setorial social idealizado, manifesto impessoal heideggeriano. Todavia, o mundo da vida não se reduz ao mundo jurídico-formal, ao formalismo outrora defendido pelo positivismo jurídico como único instrumento hábil à regulação social. Não é possível reduzir o ser ao dever-ser. Sem embargo, ao intérprete e aplicador do Direito, não se legitima essa redução de conceitos ou mesmo essa confusão entre o real e o formal jurídico. O que se aludiu são exemplos de extensão do Direito para além do direito-texto, sem, contudo, afastar-se o intérprete e aplicador do Direito do normado, mas sim, por outro lado e por paradoxal que pareça, de aproximar-se do que, de fato, é jurídiconormativo, em determinado contexto histórico social, e isso somente é possível a partir de uma visão da Fenomenologia do Direito, aplicada ao desvelamento das espécies de normas jurídicas que operam em cada meio coletivo. Com efeito, os valores, que, e.g., para Robert Alexy são alheios, ao menos diretamente, à normatividade do direito, passam a conviver harmonicamente com os princípios e as regras, formando uma terceira espécie de norma jurídica.

\section{CONSIDERAÇÕES FINAIS}

A almejada segurança jurídica não aconteceu pelas vias do positivismo. A lei e o direito puro, idealizados em uma quadra amoral reduzida ao direito-texto, debruçaram-se em crise e, com isso, a própria concepção de Direito inseriu-se em um caminho de incertezas.

A força normativa da Constituição e a sua centralização na ordem normativa tiveram papel peculiar para a formação da teoria neoconstitucional de cariz nomeadamente pós-positivista, em que os princípios foram alçados a espécie de norma jurídica dotada de carga de valor, de modo a propiciar a ponderação de normas jurídicas aplicadas ao caso concreto. $\mathrm{E}$ isso foi um grande passo para a inclusão paulatina de valores no direito e a tentativa de transposição do neoconstitucionalismo 
por meio de uma tentativa de retorno à origem: o direito natural, todavia, balizado pelo direito-texto, positivista. De fato, há o direito-texto temperado pelos valores axiomáticos, estes compreendidos como a normatividade não escrita e oriunda de padrões socioculturais que transcendem as divisas do mundo jurídico, para exarar normatividade ao lado das regras e dos princípios, fazendo submergir, sob uma óptica da fenomenologia aplicada às normas jurídicas, o subtexto do direito.

Com efeito, verifica-se o fenômeno da constitucionalização do direito, para apreender esse subtexto, ou esse contexto, pelas mãos do texto constitucional. $O$ direito adminsitrativo brasileiro encampou essa noção de direito como direito constitucionalmente qualificado, para ter acesso aos valores normativos, valores axiomáticos. A constitucionalização do Direito Administrativo leva não somente a ação administrativa ao amparo direto da Constituição, mas à percepção - com o advento da juridicidade da função executiva do Estado - do dever de identificação de valores axiomáticos que se radicam na gênese dos princípios constitucionais.

O direito, para além do direito-texto mitigado (direito-texto enfraquecido com a crise da lei e da legalidade), abre-se às possibilidades de aceitação de outras normas assentes no seio coletivo, de modo a formar a noção de subtexto do direito: aquilo que é jurídico, que é derivado do texto, mas não se faz prima facie aparente, tão somente fundante da ordem jurídica, mas não menos jurídico que ela, na medida em que faz parte dela. O retorno à origem parece ser uma boa saída dessa senda. Com efeito, reapresentam-se ao cenário jurídico, em uma via de mão dupla, o direito natural como fórmula de calibragem do direito positivo e este como muros que limitam os valores intrassistêmicos jurídicos.

A Administração Pública (e essa ação já se encontra em aplicação no exercício da jurisdição brasileira), no exercício de sua função jurídica de dizer o direito ao caso concreto (função jurídica atípica), deve-se abeberar desses matizes, nos limites não das leis restritivas, sem lastro, de seu atuar, mas sim nos limites dos valores socioculturais que dão legitimidade, como antefundamento, ao texto constitucional. Essa atuação do Estado-administração frente à ordem normativa pode ser compreendida como exercício de uma juridicidade fenomenológica. 


\section{REFERÊNCIAS BIBLIOGRÁFICAS}

ADEODATO, João Maurício. Filosofia do direito: uma crítica à verdade na ética e na ciência. 5. ed. São Paulo: Saraiva, 2013.

ALEXY, Robert. Teoria de los derechos fundamentales. Madrid: Centro de Estudios Constitucionales, 1993.

ALEXY, Robert. Teoria dos direitos fundamentais. Tradução Virgílio Afonso da Silva. Malheiros: São Paulo, 2008.

ARENDT, Hannah.. Origens do totalitarismo. Tradução Roberto Raposo. São Paulo: Cia. das Letras, 1997.

ATENCIA, Manuel. Positivismo y neopositivismo. In: Anales del Seminario de Metafísica. № 25-1991/143-154. Madrid: Ed. Universidad Complutense, 2005,

ATIENZA, Manuel. EI derecho como argumentación: concepciones de la argumentación. Barcelona: Ariel, 2006.

BARROSO, Luís Roberto. O direito constitucional e a efetividade de suas normas. Rio de Janeiro: Renovar, 2002.

BARROSO, Luís Roberto. Interpretação e aplicação da constituição. 6. ed. São Paulo: Saraiva, 2004.

BARROSO, Luís Roberto. Neoconstitucionalismo e constitucionalização do Direito (O triunfo tardio do direito constitucional no Brasil). Revista de Direito Administrativo, Rio de Janeiro, 240: 1-42, Abr./Jun. 2005.

BARROSO, Luís Roberto. A constitucionalização do direito e suas repercussões no âmbito administrativo. In: ARAGÃO, Alexandre Santos de; MARQUES NETO, Floriano de Azevedo (Coord.). Direito administrativo e seus novos paradigmas. Belo Horizonte: Fórum, 2012, p. 31-63.

BINENBOJM, Gustavo. A constitucionalização do direito administrativo no Brasil: um inventário de avanços e retrocessos. Revista Brasileira de direito Público (RBDP), Belo horizonte, Ano 4, n. 14, p. 9-53, jul/set 2006.

BINENBOJM, Gustavo. A constitucionalização do direito administrativo no Brasil: um inventário de avanços e retrocessos. Revista Eletrônica sobre a Reforma do Estado (RERE), Salvador, Instituto Brasileiro de Direito Público, n‥ 13, março/abril/maio, 2008, p. 1-44.

BITENCOURT NETO, Eurico. Transformações do Estado e da Administração Pública no século XXI. Revista de Investigações Constitucionais, Curitiba, Vol. 4. N. 1, p. 207-225, jan/abr. 2017.

BOBBIO, Norberto. Sui criteri per risolvere le antinomie. Studi per una teoria generale del diritto. Torino: Edizioni Giappichelli, 1970. 
BOBBIO, Norberto. Da estrutura à função: novos estudos de teoria do direito. Tradução de Daniela Beccaccia Visiani; revisão técnica de Orlando Seixas Bechara, São Paulo: Manole, 2007.

BONAVIDES, Paulo. Curso de direito constitucional. 19. ed. São Paulo: Editora Malheiros, 2006.

CADEMARTORI, Luiz Henrique Urquhart; OLIVEIRA, Vitória Cristina. Constitucionalização do direito administrativo e a sindicabilidade do ato discricionário. Revista Estudos Institucionais, Vol. 2, 1, 2016, p. 168-191.

CANOTILHO, J. J. Gomes. Curso de direito constitucional. Coimbra: Coimbra, 2002.

CARBONELL, Miguel. Teoría del neoconstitucionalismo: ensayos escogidos. Madrid: Trotta, 2007.

CASETTA, Elio. Compendio di diritto amministrativo. Milano: Giuffrè, 2011.

COELHO, Inocêncio Mártires. Da hermenêutica filosófica à hermenêutica jurídica: fragmentos. São Paulo: Saraiva, 2010.

CUNHA, Ricarlos Almagro Vitoriano. Ética e decisão judicial: o papel da prudência na concretização do direito. 1. ed. Curitiba: CRV, 2015.

CUNHA, Ricarlos Almagro Vitoriano. Hermenêutica e argumentação no direito. Curitiba: CRV, 2014.

DUGUIT, Léon. Des Fonctions de l'État Moderne: étude de sociologie juridique. Paris: V. Giard et E. Brière, 1894.

DUGUIT, Léon. Le droit constitutionnel et la sociologie: extrait de la revue internationale de l'Enseignement du 15 novembre 1889. Paris: Armand Colin et Cie, Éditeurs, 1889.

DWORKIN, Ronald. Uma questão de princípios. 2. ed. São Paulo: Martins Fontes, 2005.

DWORKIN, Ronald. Levando os direitos a sério. 3. ed. São Paulo: Martins Fontes, 2010.

DWORKIN, Ronald. Justiça para ouriços. Lisboa: Almedina, 2012.

ENTERRÍA, Eduardo García de. Revottition francaise et administration conteiiporaine. Collection Droit Public Positif. Paris: Economica, 1981.

FERNANDES, André Dias. A constitucionalização do Direito Administrativo e o controle judicial do mérito do ato administrativo. Revista de Informação Legislativa (RIL), Ano 51, Número 203, jul./set. 2014, p. 143-164. 
FERNANDEZ-LARGO, Antonio Osuna. El debate filosófico sobre hermenêutica jurídica. Valladolid: Secretariado de Publicaciones, Universidad, 1995.

FICHTE, Johann Gottlieb. Fundamentos do direito natural: segundo os princípios da doutrina da ciência. Lisboa: Fundação Calouste Gulbenkian, 2012.

FINDLAY, J. N. La trancendencia de la caverna. Versión española de Jesús Díaz. Madrid: Gredos, 1969.

FIORAVANTI, Maurizio. Constituición: de la antigüedad a nuestros días. Traducción de Manuel Martínez Neira. Madrid: Editorial Trotta, 2001.

GADAMER, Hans-Georg. Verdade e método. Vol. I. Petrópolis: Vozes, 2014.

GARCÍA FIGUEROA, A. El paradigma jurídico del neoconstitucionalismo. Un análisis metateórico y una propuesta de desarrollo. GARCÍA FIGUEROA, A. (Coord.). In: Racionalidad y Derecho. Madrid: CEPC, 2006, p. 265-28.

GROSSI, Paulo. A ordem jurídica medieval. São Paulo: Martins Fontes, 2014.

GÜNTHER, Klaus. Teoria da argumentação no direito e na moral: justificação e aplicação. Tradução de Claudio Molz. Introdução à edição brasileira de Luiz Moreira. São Paulo: Landy, 2004.

HART, Herbert. L. A. O conceito de direito. São Paulo: Martins Fontes, 2012.

HAURIOU, Maurice. Précis de droit administratif et droit public. Paris: Éditions Dalloz, 2002.

HAURIOU, Maurice. La gestion administrative: étude théorique de droit administratif. Paris: Éditions Dalloz, 2012.

HEIDEGGER, Martin. El ser y el tiempo. Traducción José Gaos. México: Fondo de Cultura Económica, 1993.

HESSE, Konrad. A força normativa da constituição. São Paulo: Martins Fontes, 1999.

HUSSERL, Edmund. A ideia de fenomenologia. Tradução Arthur Mourão. Coleção Textos Filosóficos. Lisboa: Edições 70, 2007.

KELSEN, Hans. Teoria pura do direito. São Paulo: Martins Fontes, 1999.

LOPES FILHO, Juraci Mourão; LOBO, Júlio César Matias; CIDRÃO, Taís Vasconcelos. O positivismo jurídico foi superado no neoconstitucionalismo? In: Revista de Estudos Constitucionais, Hermenêutica e Teoria do Direito (RECHTD), 2019, 10 (3) : 348-361.

MAYER, Otto. Derecho administrativo alemán. Tomos I. Traducción Horacio H. 
Heredia y Ernesto Krotoschin. Buenos Aires: Editorial Depalma, 1949.

MÜLLER, Friedrich. Teoria moderna e interpretação dos direitos Fundamentais: especialmente com base na teoria estruturante do direito. Anuario Iberoamericano de Justicia Constitucional, Núm. 7, 2003, p. 315-327.

Paulo: Max Limonad, 1997.

POPPER, Karl R. A lógica da pesquisa científica. São Paulo: Cultrix, 1974.

RIVERO, Jea. Droit administratif. Dix édition. Paris: Dalloz, 2011.

SARLET, Ingo Wolfgang. A eficácia dos direitos fundamentais. 8. ed. Porto Alegre: Livraria do Advogado, 2007.

SCHELER, Max. Vom Ewigen im Menschen. Text der 3. Aufl. Berlin: Berlin Der Neue Geist 1933.

STEIN, Ernildo. Seis estudos sobre "Ser e Tempo" (Martin Heidegger). Petrópolis: Vozes, 1988.

STRECK, Lenio Luiz. Verdade e consenso: Constituição, Hermenêutica e teorias discursivas. 6. ed. São Paulo: Saraiva, 2017.

VASAK, Karel. Las dimensiones internacionales de los derechos humanos. Vols. I, II e III. Barcelona: Serbal/Unesco, 1984.

VICO, Giambattista. Ciencia nova. Tradução de José Vaz de Carvalho. Lisboa: Calouste Gulbenkian, 2005.

WEIL, Prosper; POUYAUD, Dominique. Le droit administratif. Dix-septième édition corrigée. Paris: Puf, 1997.

ZAGREBESLKY, Gustavo. La ley y su justicia: tres capítulos de justicia constitucional. Madrid: Trotta, 2008.

ZANOBINI, Guido. Corso di diritto amministrativo. Milano: Giuffrè,1947.

Recebido em 25/06/2019 Aprovado em 26/09/2019 Received in 25/06/2019 Approved in 26/09/2019 